\title{
Fatal cholestatic hepatitis in an infant: An unusual etiology
}

\author{
MARK R Oliver mbBS, AlfRedo PinTo mD, R BRENT SCOTT MDCM
}

\begin{abstract}
MR OlIVER, A PINTO, RB SCOTT. Fatal cholestatic hepatitis in an infant: An unusual etiology. Can J Gastroenterol 1995;9(4):217-220. An infant girl who presented with cholestasis and hepatitis that rapidly progressed to fulminant liver failure is reported. Postmortem examination yielded a diagnosis of demonstrated extensive hepatic necrosis due to adenovirus type 5 infection which had developed in the setting of an occult primary immunodeficiency (severe combined immunodeficiency). The aim of this report is to alert the physician to a rare cause of cholestasis and hepatitis in infancy. Recognition of the combination of adenoviral infection with underlying primary immunodeficiency is a prerequisite to the provision of genetic counselling.
\end{abstract}

Key Words: Adenovirus, Cholestasis, Hepatitis, Immunodeficiency

\section{Hépatite choléstatique fatale chez un nourrisson : étiologie inhabituelle}

RÉSUMÉ : Le cas d'un nourrisson de sexe féminin qui a présenté une choléstase et une hépatite ayant progressé vers une insuffisance hépatique fulminante est résumé ici. L'autopsie a permis de poser un diagnostic de nécrose hépatique étendue attribuable à une infection à adénovirus de type 5 qui s'était développée dans le contexte d'une immunodéficience primitive occulte (immunodéficience combinée grave). Le but de ce rapport est de sensibiliser les médecins à une cause rare de choléstase et d'hépatite chez les nourrissons. L'observation d'une infection adénovirale combinée à une immunodéficience primitive sous-jacente est essentielle à tout counselling génétique.

$\mathrm{O}_{\mathrm{m}}$ BSTRUCTIVE JAUNDICE REQUIRES prompt investigation to identify an etiology and institute specific supportive and/or therapeutic measures to prevent morbidity and mortality. We report a three-month-old infant girl who presented with cholestatic jaundice and hepatitis that progressed to fulminant hepatic failure due to adeno- virus type 5 infection. Postmortem diagnosis of severe combined immunodeficiency syndrome (SCIDS) was made. Infection, viral or bacterial, can be a recognized but less common cause of this clinical picture in infancy $(1,2)$. However, neither adenovirus infection nor immunodeficiency has been included as a cause of hepatitis or

Department of Pediatrics and Pathology, Alberta Children's Hospital and University of Calgary, Calgary, Alberta

Correspondence and reprints: Dr R Brent Scott, Department of Pediatrics, Health Science Centre, 3330 Hospital Drive NW, Calgary, Alberta T2N 4N1. Telephone 403-220-4556, Fax 403-283-3028, e-mail scott@acs.ucalgary.ca cholestasis during infancy in comprehensive summaries of the differential diagnosis (1-3).

\section{CASE PRESENTATION}

Clinical history: A three-month-old female born to unrelated Mennonite parents was transferred from a regional centre (following a one-week admission) to the Alberta Children's Hospital in Calgary, Alberta with cholestatic jaundice and hepatitis as indicated by total bilirubin of $68 \mu \mathrm{mol} / \mathrm{L}$ (normal less than 32) with a conjugated bilirubin of $57 \mu \mathrm{mol} / \mathrm{L}$ and elevated liver enzymes (aspartate aminotransferase 542 $\mathrm{U} / \mathrm{L}$ [normal 0 to 30] and alkaline phosphate $1721 \mathrm{U} / \mathrm{L}$ [normal 75 to 400 ]). A tentative diagnosis of biliary atresia had been made at the referring institution on the basis of absent excretion of bile into the small intestine during a nuclear medical hepatobiliary scan. However, there were some unusual features that weighed against the transfer diagnosis and suggested an infectious etiology. First, the child had also presented with fever, leukopenia (total white blood cell count $3.2 \times 10^{9}$ cells/L, normal 5 to 18.5) and microcytic, hypochromic anemia (hemoglobin $59 \mathrm{~g} / \mathrm{L}$, normal 95 to 155). Second, the infant also had a history of failure to thrive, with a recent onset of otitis externa. Before transfer the infant commenced a course of both broad spectrum intravenous antibiotics and an oral antifungal agent. Cultures of urine and blood obtained before treatment was initiated did not subsequently 
TABLE 1

Laboratory investigations

\begin{tabular}{|c|c|c|c|}
\hline & On admission & Before death & Normal values \\
\hline Hemoglobin (g/L) & 94 & 75 & $110-147$ \\
\hline White blood cells $\left(\times 10^{9} / \mathrm{L}\right)$ & 3 & 4.9 & $6-18$ \\
\hline Lymphocytes (x109/L) & 0.5 & 1.8 & $2.8-14.4$ \\
\hline Platelets $\left(\times 10^{9} / \mathrm{L}\right)$ & 167 & 75 & $150-550$ \\
\hline Prothrombin time (s) & 15.1 & 28 & $11.9-17.7$ \\
\hline $\begin{array}{l}\text { Activated partial thromboplastin time } \\
\text { (s) }\end{array}$ & 33 & $>150$ & $23.7-37.9$ \\
\hline Fibrinogen (g/L) & 2.0 & 1.4 & $2-4$ \\
\hline D-dimers (fibrinogen equivalent units) & $<0.05$ & $<0.05$ & $<0.5$ \\
\hline Total bilirubin ( $\mu \mathrm{mol} / \mathrm{L})$ & 55 & 108 & $5-23$ \\
\hline Conjugated bilirubin ( $\mu \mathrm{mol} / \mathrm{L})$ & 25 & 76 & $0-10$ \\
\hline Gamma glutamyltransferase (U/L) & 1518 & 652 & $16-43$ \\
\hline Aspartate aminotransferase (U/L) & 1656 & 23,250 & $12-50$ \\
\hline Alanine transaminase (U/L) & 480 & 1740 & $5-40$ \\
\hline Albumin (g/L) & 24 & 22 & $35-50$ \\
\hline Immunoglobulin G (U/L) & 0.73 & - & $3.45-12.36$ \\
\hline Immunoglobulin A (U/L) & $<0.07$ & - & $0.14-1.23$ \\
\hline Immunoglobulin M (U/L) & 0.17 & - & $0.43-1.73$ \\
\hline Alpha-1 antitrypsin (U/L) & - & 3.48 & $0.85-2.65$ \\
\hline Urinary reducing substances & Negative & & \\
\hline
\end{tabular}

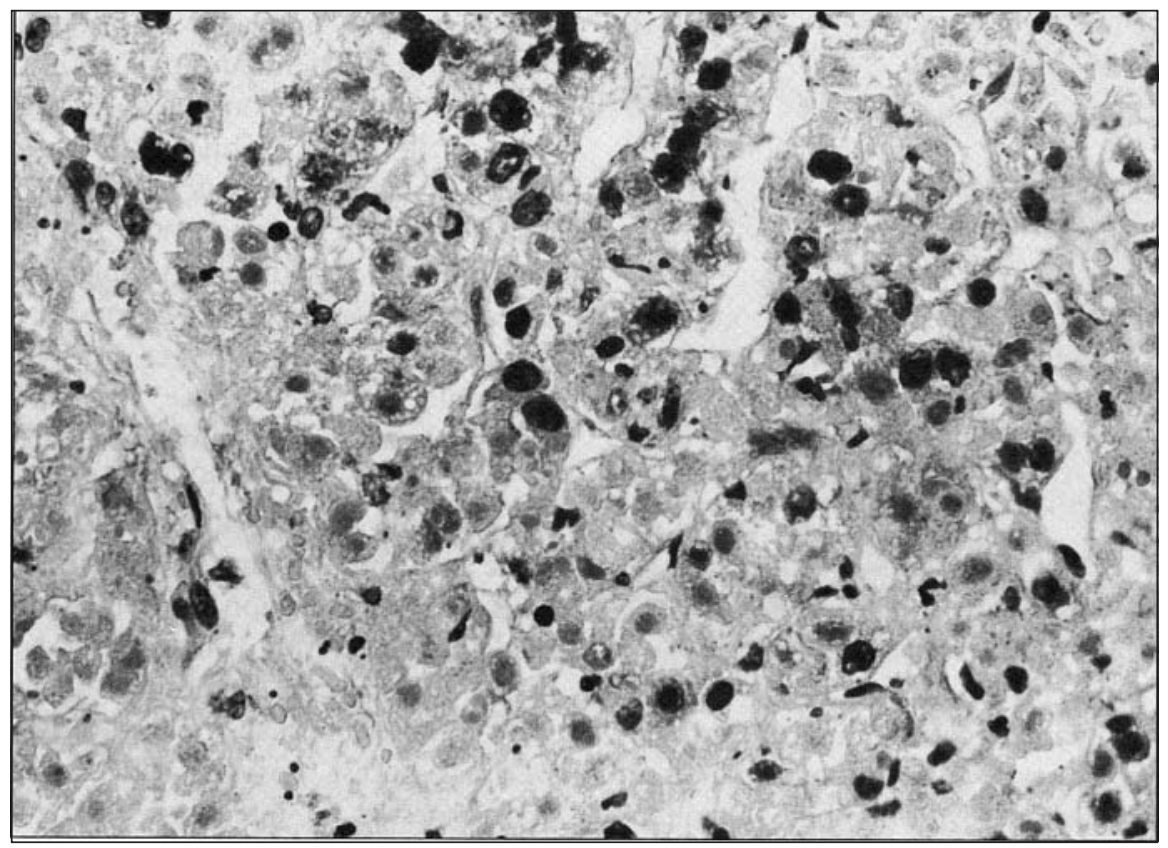

Figure 1) Light microscopy demonstrates extensive necrosis of the hepatocytes without a significant inflammatory response. Some hepatocytes contain intranuclear inclusions consistent with viral infection (hematoxylin and eosin $\times 262$ )

grow either bacterial or fungal pathogens.

On admission to the Alberta Children's Hospital, the following additional information was obtained. The patient had been born at term (weight $2.8 \mathrm{~kg}$ ) and at home, in a Mennonite hospital, at which time she was jaundiced and passing both acholic stools and dark urine. These symptoms were accompanied by a discharging right ear and pallor. She had never been immunized or been given any prescribed or nonprescribed medications. The patient's 19-month-old sibling was well. Several unexplained deaths in the first years of life were reported on the maternal side of the family.

Physical examination confirmed failure to thrive; both the patient's height and weight were below the fifth percentile. She was afebrile, and appeared pale, jaundiced and poorly nourished. There was a yellow discharge from her right ear due to otitis externa and mild oral candidiasis. Both tonsillar and lymphoid tissue were clinically present. She was noticeably irritable on stimulation; however, there was no evidence of focal neurological signs. Her liver was $7 \mathrm{~cm}$ in span and her spleen was palpable $2 \mathrm{~cm}$ below the left costal margin. There was no other clinical evidence of chronic liver disease.

Laboratory investigations performed on admission are summarized in Table 1 . Within $12 \mathrm{~h}$ of admission the patient suffered a significant deterioration characterized by the clinical findings of shock, bleeding diathesis and deteriorating liver function. She received supportive care including volume expansion with fresh frozen plasma, antibiotics, pooled immunoglobulin and vitamin K. Serological investigations for hepatitis $\mathrm{A}, \mathrm{B}$ and $\mathrm{C}$, cytomegalovirus, toxoplasmosis, herpes simplex and human immunodeficiency virus-1 were negative. Plasma amino acids and urinary organic acid profile failed to detect an underlying metabolic disorder. Repeat blood and urine cultures were negative for bacterial or fungal organisms. Rotavirus was isolated from the stools and adenovirus cultured from the patient's nasopharynx eight days following admission to the Children's Hospital. Despite all supportive efforts the patient's coagulopathy persisted (uncorrected by blood products and vitamin $\mathrm{K}$ ) and her liver function continued to deteriorate (Table 1 ). In addition, she devel- 
oped significant neurological dysfunction characterized by irritability, opisthotonos, apnea and seizures in the absence of evidence of an intracranial bleed on cerebral computed tomographic scan (or later at autopsy). She died eight days following admission.

Autopsy findings: Autopsy revealed a diffuse granular liver, which on histological assessment showed extensive areas of necrosis with minimal inflammation and normal portal tracts. Hepatocytes at the periphery of necrotic areas contained round nuclei with acidophilic inclusions suggestive of viral infection (Figure 1). Electron microscopic examination of liver tissue revealed the presence of adenovirus particles (Figure 2). The adenovirus was serotyped as type 5 by standard neutralization tests using adenovirus type 5 reference antisera (4). At the time of autopsy, adenovirus was cultured from stools, heart, lungs, liver, cerebrospinal fluid and throat, reflecting terminal viremia. There was no evidence of inflammation or viral inclusion bodies detected in other organs apart from the liver. Examination of the reticuloendothelial system disclosed a small thymus with complete depletion of lymphocytes, dysplastic epithelium and absence of Hassall's corpuscles. The lymph nodes, spleen and Peyer's patches were depleted in lymphocytes and showed no evidence of germinal centres. These histological findings are characteristic of severe combined immunodeficiency (5).

\section{DISCUSSION}

A diagnosis of SCIDS, a heterogenous group of disorders characterized by a gross functional impairment of both $\mathrm{T}$ and $\mathrm{B}$ lymphocytes, was made in our patient. This diagnosis is supported by both laboratory and autopsy findings including the presence of lymphocytopenia, hypogammaglobulinemia, thymic dysplasia and generalized lymphoid hypoplasia. There is usually a positive family history obtained in 50\% of patients with SCIDS which may reflect an autosomal recessive, dominant or X-linked pattern of inheritance (6). It is possible that in this patient's Mennonite background there is an unrecog-

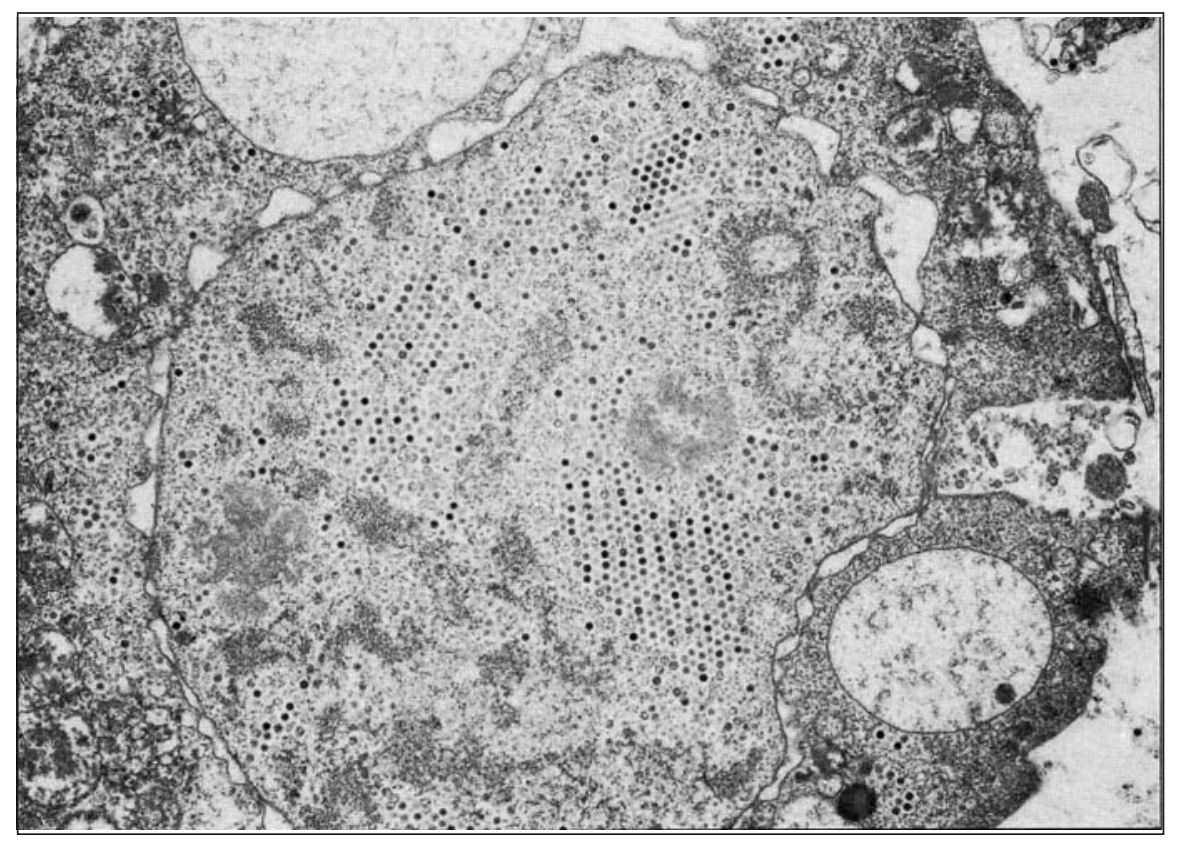

Figure 2) Hepatocyte showing the typical crystalline array of adenovirus particles within the nucleus (uranyl acetate-lead citrate $\times 5216$ )

nized basis for recessive inheritance; however, the precise inheritance of her disease remains to be elucidated.

Adenovirus can, like many other viruses, take advantage of an abnormal immune system and produce either persistent or generalized infections (4,7-11). In the immunocompromised patient with adenoviral infection there is a case fatality rate of over $50 \%$ in those who present with hepatitis compared with less than $10 \%$ in the immunocompetent patient (9). When adenoviral infection occurs as a result of a primary immunodeficiency, over $90 \%$ of cases are associated with SCIDS (9). Of the 19 reported adenoviral induced fatalities in patients with SCIDS, there has been only one previously reported case with adenovirus type 5 infection, and in that patient the clinical picture and outcome was similar to that described for our patient (10).

There is no specific treatment for SCIDS although a variety of natural and synthetic products have been used with minimal success, including thymic humoral factor, pooled immunoglobulin $G$ (which was used unsuccessfully in our patient) and interferon (9). More recently ganciclovir has shown some promise in disseminated adenoviral infection after liver transplantation (12).
Lastly, successful treatment of fulminant viral hepatitis (ECHO virus type 11) by orothotopic liver transplantation has been reported in an infant (13). Despite post-transplant immunosuppressive drug therapy, this latter patient's ECHO viral hepatitis did not recur. Such aggressive treatment warrants further assessment in the case of certain viral-induced hepatic infections. However, because of our patient's underlying severe immunodeficiency syndrome we do not believe that liver transplantation would have been an appropriate therapeutic option.

\section{CONCLUSIONS}

The aim of this report was to alert the physician to a rare cause of cholestasis and hepatitis in infancy. While adenoviral hepatitis and cholestasis in infants with SCIDS is rare, and usually lethal even with early recognition and treatment, it should not go unrecognized because of the need to provide genetic counselling to the family.

ACKNOWLEDGEMENTS: The authors thank Roberta Funk for typing the manuscript. Mark Oliver is a recipient of an Alberta Children's Hospital Foundation Fellowship. 


\section{REFERENCES}

1. Balistreri WF. Neonatal cholestasis: lessons from the past, issues for the future. Semin Liver Dis 1987;7:61-6.

2. Felber S, Sinatra F. Systemic disorders associated with neonatal cholestasis. Semin Liver Dis 1987;7:108-18.

3. Moyers MS, Balistreri WF. Prolonged neonatal obstructive jaundice. In: Walker WA, Durie PR, Hamilton JR, Walker-Smith JA, Watkin JB, eds. Pediatric Gastrointestinal Disease. Pathophysiology, Diagnosis and Management, vol 2. Toronto: BC Decker, 1991:835-48

4. Washington K, Gossage DL, Gottfried MR. Pathology of the liver in severe combined immunodeficiency and Di George syndrome. Pediatr Pathol 1993;13:485-504.

5. Linder J, Purtillo DT. Current concepts of immunodeficiency disorders. Mod Pathol 1990;3:524-44.

6. Waldmann TA. Immunodeficiency diseases: primary and acquired. In: Samter M, Talmage DW, Frank MM, Austen KF, Claman HN, eds. Immunological Diseases, 4th edn. Toronto: Little, Brown \& Co, 1988:411-67.

7. Ohbu M, Sasaki K, Okudaira M, Iidaka $\mathrm{K}$, Aoyama Y. Adenovirus hepatitis in a patient with severe combined immunodeficiency. Acta Pathol Jpn 1987;37:655-64.

8. Wigger HJ, Blanc WA. Fatal hepatic and bronchial necrosis and adenovirus infection with thymic alymphoplasia. N Engl J Med 1966;275:870-4.

9. Heirholzer JC. Adenovirus in the immunocompromised host. Clin Microbiol Rev 1992;5:262-74

10. South MA, Dolen J, Beach DK, Mirkovic
RR. Fatal adenovirus hepatic necrosis in severe combined immunodeficiency. Pediatr Infect Dis J 1982;1:416-9.

11. Spencer MJ, Cherry JD. Adenoviral infections. In: Feigin KD, Cherry JD, eds. Pediatric Infectious Disease, 3rd edn. Philadelphia: WB Saunders Co, 1992:1670-87.

12. Wreghitt TG, Gray JJ, Ward KN, et al. Disseminated adenoviral infection after liver transplantation and its possible treatment with ganciclovir. J Infect 1989;19:88-9.

13. Chuang E, Maller ES, Hoffman MA, Hodinka RL, Altschuler SM. Successful treatment and fulminant Echovirus 11 infection in a neonatal by orthotopic liver transplantation. J Pediatr Gastroenterol Nutr 1993;17:211-4. 


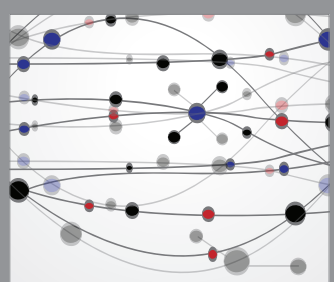

The Scientific World Journal
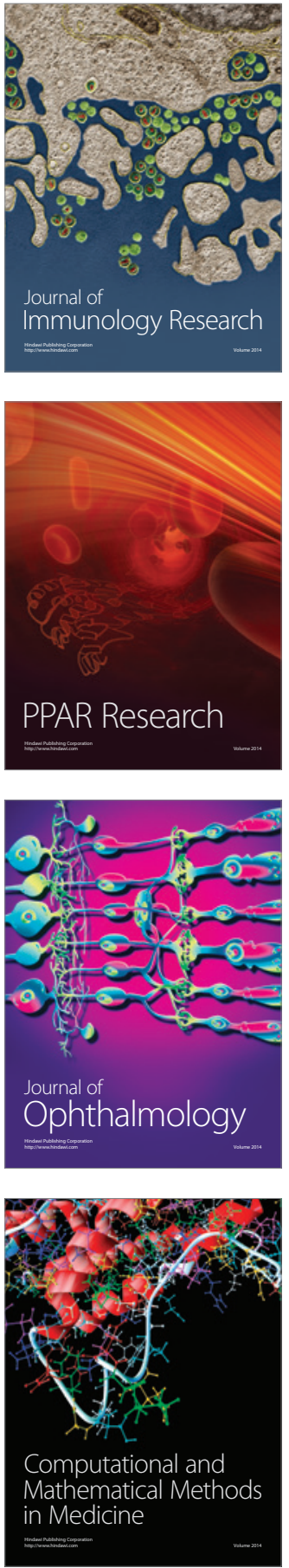

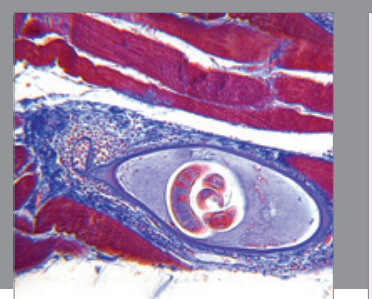

Gastroenterology Research and Practice

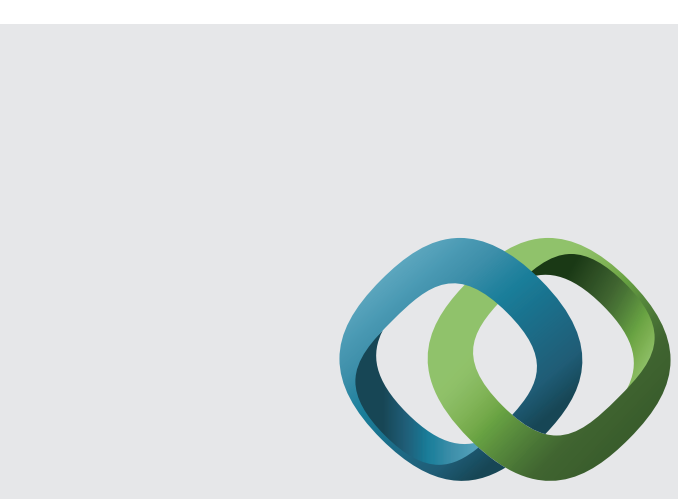

\section{Hindawi}

Submit your manuscripts at

http://www.hindawi.com
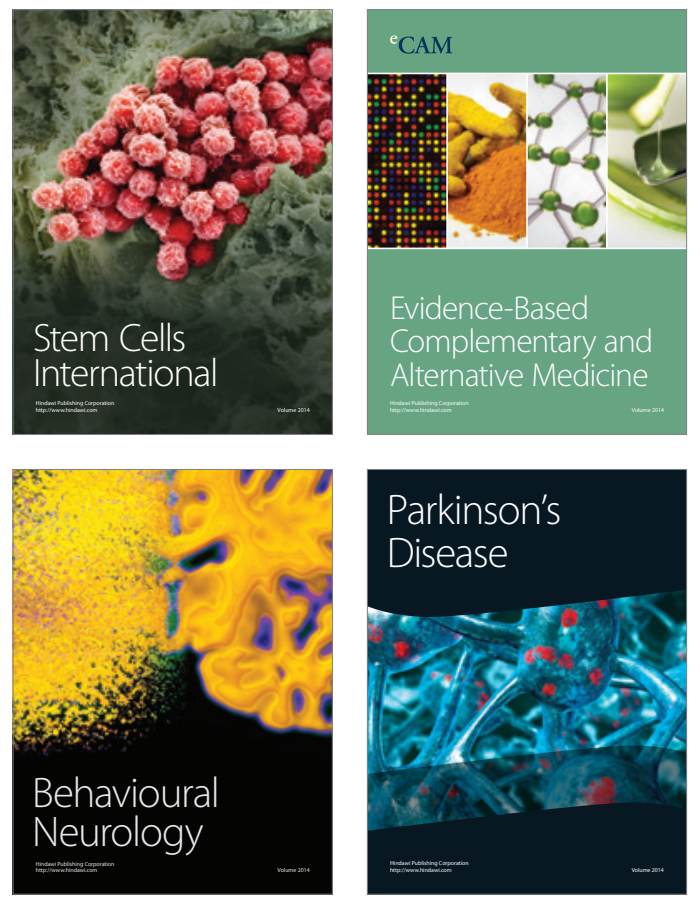
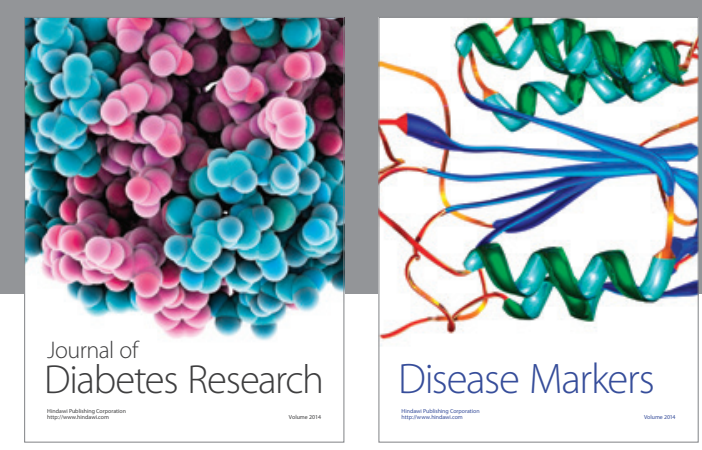

Disease Markers
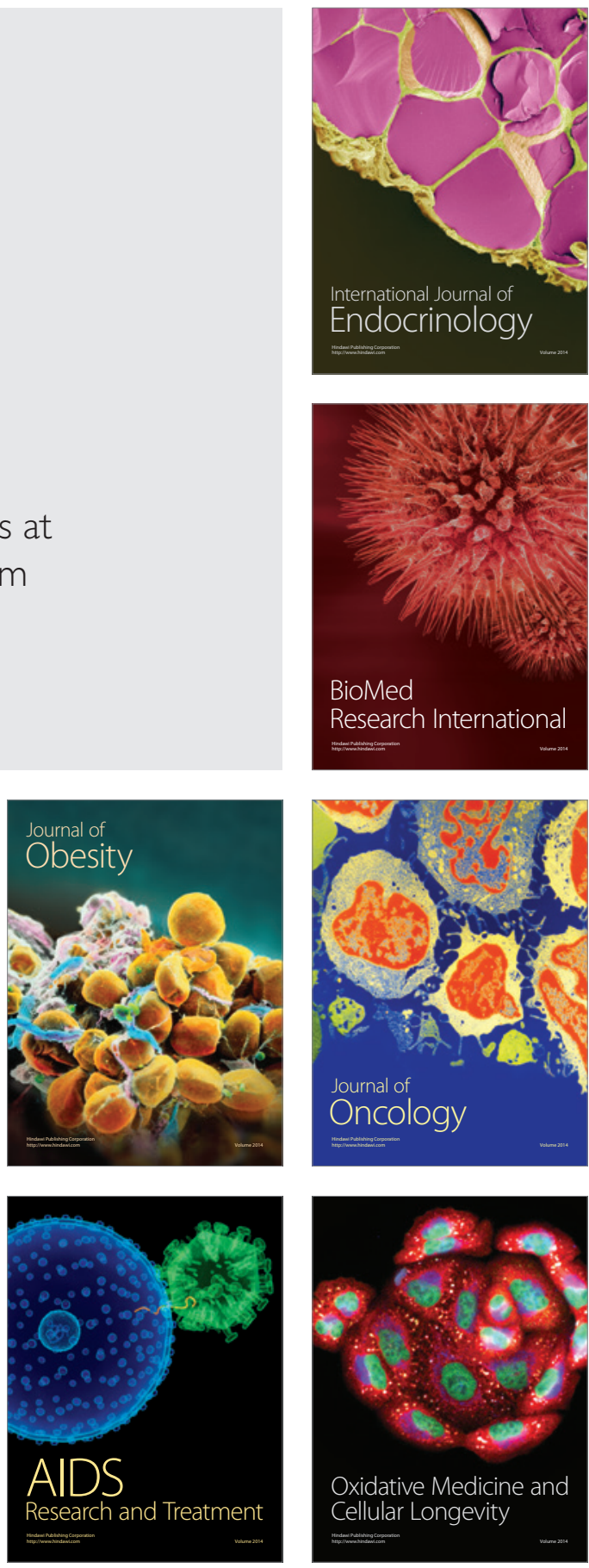